\title{
Ideology in College English Teaching under the Background of Courses for Ideological and Political Education
}

\author{
Ming Zhang1, Shenglu Li ${ }^{2}$ \\ ${ }^{1}$ Zhejiang Yuexiu University, Shaoxing, China \\ ${ }^{2}$ Zhejiang International Studies University, Hangzhou, China \\ Email: 20131050@zyufl.edu.cn, 312919554@qq.com
}

How to cite this paper: Zhang, M. and Li, S.L. (2021) Ideology in College English Teaching under the Background of Courses for Ideological and Political Education. Open Access Library Journal, 8: e7180. https://doi.org/10.4236/oalib.1107180

Received: January 24, 2021

Accepted: February 20, 2021

Published: February 23, 2021

Copyright $\odot 2021$ by author(s) and Open Access Library Inc.

This work is licensed under the Creative Commons Attribution International License (CC BY 4.0).

http://creativecommons.org/licenses/by/4.0/

\begin{abstract}
The research on ideological issues has been studied for a long time, but it has not been widespread in all the research areas. The numbness and even indifference of the public to the ideological issues is precisely the biggest crisis in dealing with this situation. This paper invests and analyzes ideological data of university English teaching from cognitive competence, environment, features and measures under nowadays background. At the same time, this paper supplies some useful measures of consolidating ideological security from five aspects of ideological understanding, language ontology, political tutelage, internet plus innovation and social attribute of language.
\end{abstract}

\section{Subject Areas}

Culture, Education, Linguistics

\section{Keywords}

Ideology, College English Teaching, Ideological and Political Education

\section{1. 引言}

2016 年 12 月 7 日至 8 日在全国高校思想政治工作会议上, 习近平强调, 要用好课堂教学这个主渠道, 各类课程都要与思想政治理论课同向而行, 形 成协同效应。而早在 2013 年在全国宣传思想工作会议上习近平就强调, 意识 形态工作是党的一项极端重要的工作, 能否做好意识形态工作, 事关党的前 途命运, 事关国家长治久安, 事关民族凝聚力和向心力。英语教学在我国高 校已开展几十年，英语既作为一种语言也作为一种工具裹挟着以美国为首的 西方国家意识形态，导致我国主流文化、意识形态与价值观面临外来文化与 
意识形态及价值观的侵蚀[1]。本文认为当下国内外语界极少在教学层面深入 涉足意识形态问题, 更较少上升到国家意识形态建设的战略考量。所以说, 虽然关于 “意识形态” 的研究由来已久, 但是在高校英语教学领域深入开展 意识形态与教学的相关研究, 仍有较高的学理意义和政治意义。

\section{2. “意识形态” 问题起源与影响}

“意识形态” 是一个哲学范畴, 是哲学史发展的理论结晶, 虽然在什么 是 “意识形态” 以及其起源和影响上各有所云, 扑朔迷离, 但并不影响我国 众多学者的普遍共识。如俞吾金[2]论述为孔迪亚克的学生托拉西创造了 “意 识形态” 这一概念, 当代法国学者阿尔都塞提出了 “人是意识形态的动物” 这一著名见解, 而以历史唯物主义为基础和出发点的马克思意识形态学说乃 是真正科学的意识形态学说。意识形态是相对稳定的价值观念, 是价值观的 表达, 是一种动态的历史过程, 其核心是价值取向。党的十九大报告再次提 出, 要牢牢掌握意识形态工作领导权。意识形态对社会生活具有引导、规范 和整合的功能, 是国家政治安全的重要保障, 是国家经济安全的精神动力和 文化安全的核心内容, 在国家主权和根本利益的维护上, 意识形态起到至关 重要的作用[3]。

意识形态理论历经数百年发展依然能够不断增强自身活力, 关键在于其 自身的与时俱进。意识形态阵地是国家的核心利益, 也是国际社会博弯的重 要砝码。在社会主义现代化建设中不断形成和发展起来的社会主义意识形态 虽然具有很强的凝聚力和号召力, 但是依然面临许多挑战：国际上, 西方一 些敌对势力始终没有放弃颠覆中国的政治野心, 在和平年代, 意识形态的渗 透成为西方社会和平演变中国的重要手段。美国在其外交事务报告中就曾宣 扬, 可以 “运用现代传播工具和传播技术, 是有可能触及大部分有影响的国 民一一给他们提供信息、影响他们的态度……促动他们走上特定的行动方 向” ，从而解构其主流意识形态认同的群众基础 [4]。其它还有如 “和平队”、 “全国争取民主基金会”、“美国之音”、“亚洲基金会” 和 “富布莱特奖学金 计划” 等主要意识形态输出机构, 通过同外国进行科技文化交流或信息传播 来达到意识形态渗透的目的, 以服务美国的对外政策[5]。即使在国内, 随着社 会多元化的发展, 也形成了多元利益主体, 也存在多种社会文化并存的现象 [6]。这些因素不但摚乱了社会主义主流意识形态的发展, 而且对我国的意识 形态安全构成了威胁, 更全面、深刻干扰了社会主义现代化建设的方方面面。

\section{3. 高校意识形态问题研究简述}

“意识形态” 问题研究由来已久, 并且经常和国家安全问题紧密相连。 主题检索和计量可视化分析我国知网(CNKI) 数据库发现, 改革开放以来, “意 识形态” 主题研究呈现总体上升趋势, 其中以政策研究类文章居多。尤其 2000 年以来此主题研究增长迅速, 大有爆发之势(如图 1)。学科分类主要涉及政治、 文学、马克思主义、教育、哲学、语言、文化等; 相关研究的关键词有意识 形态、马克思主义、思想政治教育、大学生、社会主义核心价值体系等(如图 
2)。外语教育教学中的意识形态研究主要涉及翻译策略、语篇分析、文化比 较、语言政策等。已有不少学者对当下我国的英语教学提出了思考和警醒。 如宋广强和章凤红[3]看到了我国意识形态安全面临的严峻挑战: 包括西方意 识形态联合行动的压力、经济全球化带来的挑战、社会阶层分化加大了主流 意识形态社会整合难度、以及信息网络化对我国意识形态安全带来新的风险。 在高等教育领域, 王永贵 \&路媛 [4]指出 “衡量意识形态的标准不是合理性和 科学性, 而是社会职能”。抓好高校的意识形态建设, 是学校和教师必须承 担的教育功能和责任。具体到高校外语教学上, 穆风良 [7]曾指出, 意识形态 在外语教学中首先是通过语言政策来体现的, 虽然英语在中国是作为一门外 语来教学和应用的, 但依然是控制社会和实施权利的首要媒介。而王景洁[8] 简要提出了 “通过增强教师的跨文化交际意识, 引导学生认同社会主义核心 价值观, 克服 “中国文化失语症”, 培养学生的文化自信” 等举措来维护高 等教育的意识形态阵地。以上发现, 意识形态问题不单单是国家或政治层面 需要考量的问题, 而是全社会各层面都需要引起重视的问题, 高校更是意识 形态冲突和斗争之地。过去高校对意识形态的关注主要还是集中在特定专业 或特定研究人员身上, 尚没有形成大众的普遍关心。而对意识形态问题的麻 木甚至不以为然恰恰是当下应对意识形态问题最大的危机。

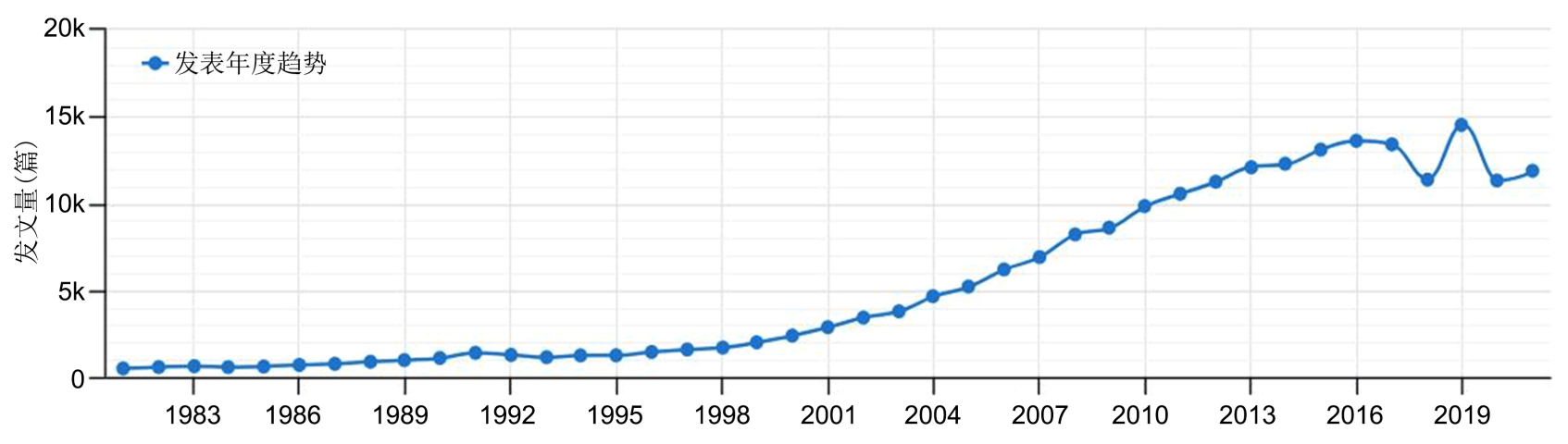

图 1. “意识形态” 研究发文数量趋势表

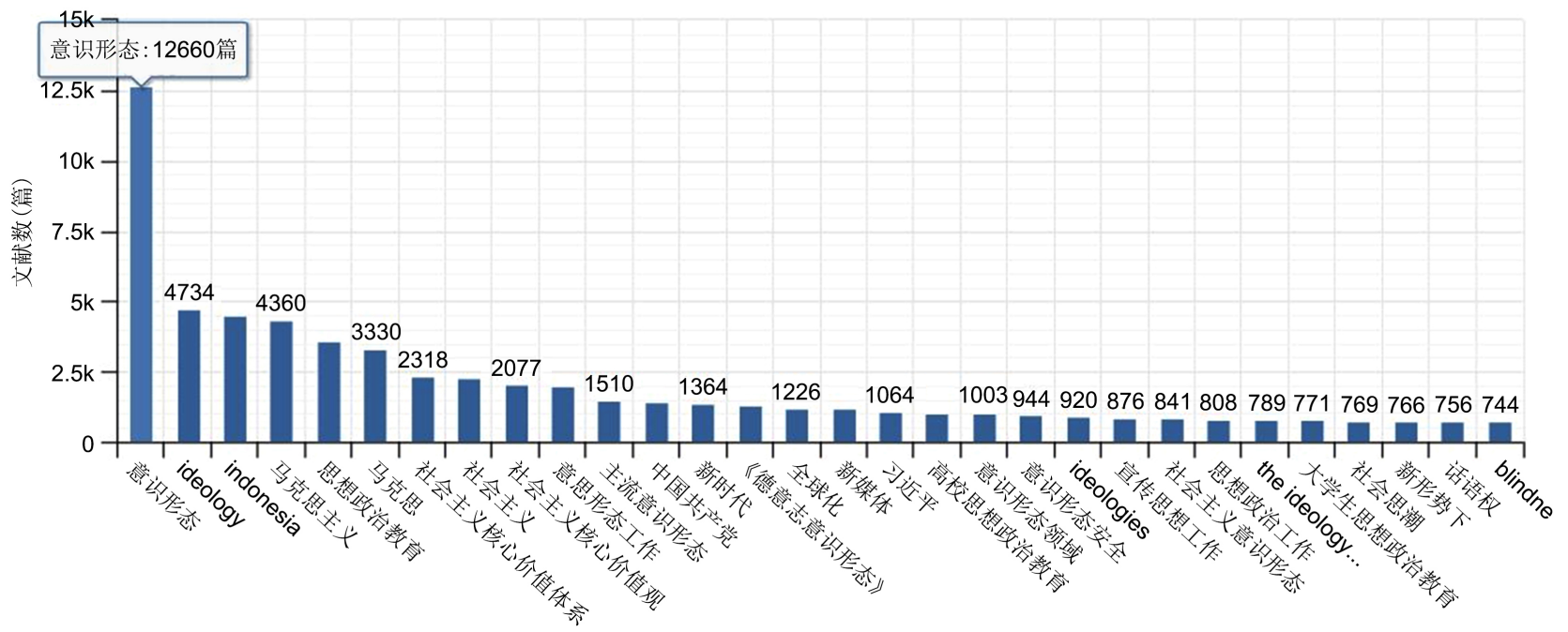

图 2. 意识形态研究主题分布表 


\section{4. 当下高校英语教学中的意识形态问题特征}

司显柱[1]指出, 英语经常被看作一种中性的交流工具, 而不是一种文化 或意识形态的载体, 这种忽视导致英语教学中的许多行为和话语加强了西方 的话语霸权和意识形态在中国的渗透。这种持续地渗透已经熏染了高校英语 教学的各个层面, 却不易被察觉。夏远超[9]也提出当下英语教学理论跟随西 方英语国家, 但在教学理论研究上与西方英语国家差距较大、英语教学过于 重视西方文化, 淡化传统文化以及过于重视英语学习忽视母语学习的现状。 在回顾前人研究的基础上, 通过访谈观察、教材研究, 也部分凸显了当下英 语课堂存在的意识形态认识模糊现象。为进一步探求问题, 本论文设计并分 析了来自全国范围各层次高校的 100 份调查问卷, 对象有全国双一流高校、 普通本科高校和高职类院校英语专业和大学英语课堂, 包括老师和学生, 其 中男生 23 人, 女生 77 人, 35 岁以上的调研对象占比 17\%, 17 22 岁占比 $74 \%$, 也就是有效答卷来源以在校学生为主。问卷测试维度包括认知、环境、特征、 举措四个模块, 问题 Q1-Q5 主要测量被调查对象的性别、年龄、专业、身份 等要素, 问题 Q6-Q29 共 24 个单项选择题, 包含由 A 到 E 共 5 个选项分别对 应数字 $1 \sim 5$, 根据个人回答的肯定程度, 越肯定的回答越接近数字 5 。Q30 设 置了一个开放性问答题, 测量被调查者的主观能动性与相关建议。总体而言, 问卷数据基本达到了设计预期, 美中不足的是多数问题选项 “ 3 ” 的比例偏高, 也就是不偏不倚的中间等级。在深入调研中发现, 被调查者不知道、不愿意、 不熟悉如何选择或者无明显偏好两极, 居中从众心理影响较大。综上发现, 当下我国高校英语教学意识形态生态状况主要存在以下特征:

\section{1. 意识形态的校园认知方面}

在 Q6 “你对意识形态概念的认识” 一题中(图 3), 48\%的调查对象都选 择了数字 3 , 只有 $18 \%$ 的调查对象选择了最肯定的数字 5 , 而平均线以下的选 择达到 $23 \%$, 说明被调查对象对意识形态的概念并不十分熟悉。Q7 “你认为 高校老师和学生关注意识形态问题的必要性”一题中, 有 35\%的调查对象选 择了数字 3 , 有 $37 \%$ 的人选择了数字 5 很有必要, 说明被调查对象对意识形 态的关注度不够。Q8 “你接触的英语教师存在意识形态问题吗? ” 有 $32 \%$ 的 人选择了数字 3 , 只有 $34 \%$ 的人选择了数字 1 , 说明被调查对象并不十分了解 英语教师是否存在意识形态问题。Q9 “你认为西方国家会利用英语向国内校 园进行意识形态渗透吗? ” (图 4) 有 $43 \%$ 的人选择了数字 3 , 而选择数字 1 和 2 的人高达 $26 \%$, 选择最高级别肯定的人只有 $13 \%$, 说明被调查对象缺乏对 西方意识形态输出的必要戒备和防御。Q15 “你认为接触的互联网信息有意 识形态问题吗? ” 平均以下否定回答的比例占 $82 \%$, 也就是作为意识形态问 题泛滥的互联网世界, 绝大多数被调查对象认为不存在意识形态问题。以上 数据基本反映出校园里对意识形态概念和存在性的基本认识明显不足, 对西 方意识形态渗透的警觉和防范不足。

\section{2. 教材与授课内容方面}

Q10 “英语课上有人和你谈论过意识形态问题吗? ” 选择数字 $1 、 2 、 3$ 
的人竟然占比 $94 \%$, 也就是说基本上很少在课堂上谈论意识形态问题。对应 的 Q11 “你对西方价值观的认可度? ” 有 $47 \%$ 的人选择了数字 3, 38\%的人选 择了数字 2 , 只有 $12 \%$ 的人选择了最低级的数字 1 代表不认可西方价值观。 当下外语教学中的理念、方法、素材多源于国外, 传递的是国外文化的价值 观。比如马丁 - 路德 - 金《我有一个梦》以诗意般的语言、动人的情感、坚 定的信念著称, 多年来也被国内英语学习者追捧和模仿, 却很少人思考其现 实意义和潜在的文化暗示。实际上 《I have a dream》来源于《圣经》, 扎根 于 “美国梦”，传递了大量 “上帝造人”、“赎罪”、“圣爱”、“上帝万 能” 等并不符合中国国情的价值观。目前国内多数高校都开设一门英语报刊 选读课, 王祥兵 [10]从中发现了很多异化翻译, 其主要目的是拉近与中国读者 之间的心理距离, 增加其灌输的美国价值观和意识形态对中国读者潜移默化 的影响。现行英语课教材出现频率最高的一些词汇也绝大多数暗含美国等西 方国家价值观的暗示。在 Q13 “你相信赎罪说、上帝万能说吗? ” 问卷中, 有数字 3 以上肯定回答相信的人占 $21 \%$ 。Q14 你认为接触的英语教材、学习 资料有意识形态问题的平均以上肯定回答 $35 \%$ 。Q16 “你认为校园里庆祝圣 诞节、情人节、感恩节等认可吗? ” (图 5)平均以上的认可选择高达 $59 \%$, 只 有 $19 \%$ 的人选择数字 1 不认可。

\section{3. 教师言传身教与自主学习方面}

老师的话语权对学生主流意识形态的形成有重要影响, 即使教师无意识 的话语也会对学生产生重要的影响。现有的外语教师对意识形态安全问题多 数麻木, 御外意识淡薄, 许多英语教师从未思考或意识到意识形态问题。尤 其是不少通过国家交流计划或者自费出国境进修、访学后, 不但自身的学识 和知识结构多为 “西学”, 而且早已潜移默化地接纳了西方的价值体系, 以 为自己已然具备国际化的思维, 实则是其思想最容易受到侵害, 其归国后心 悦诚服地接受西方的价值观, 对西方大加赞扬, 并且不加批判地传给学生;

答题人数: 100

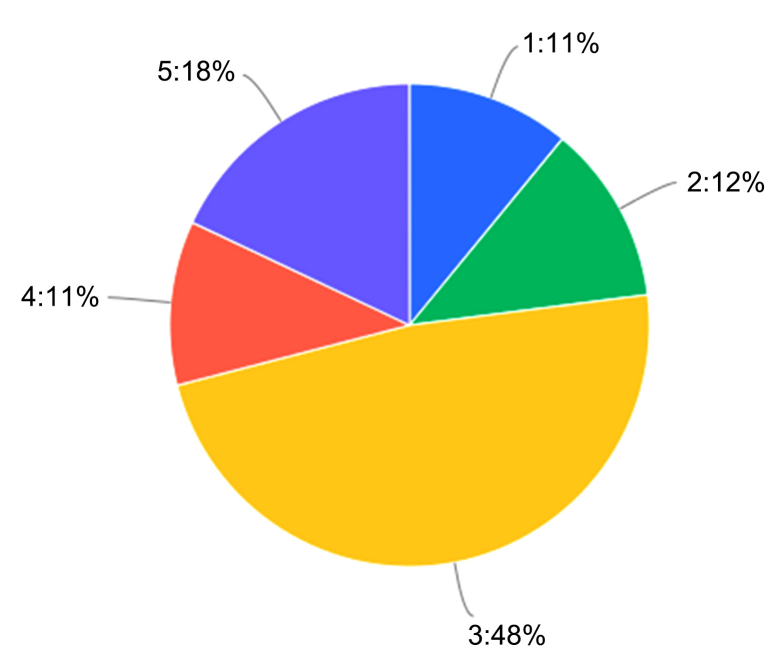

图 3. Q6 你对 “意识形态” 概念的认识 
答题人数: 100

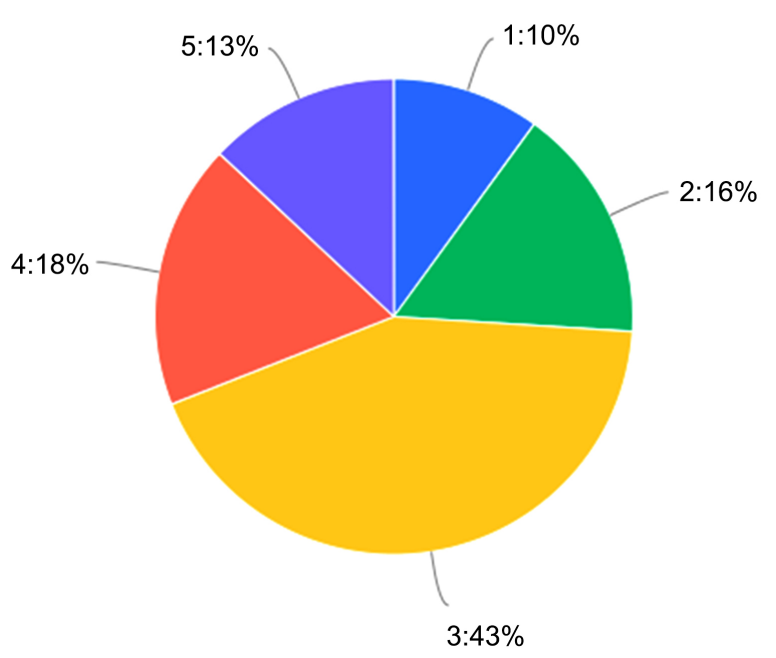

图 4. Q9 你认为西方国家会利用英语向国内校园进行意识形态渗透吗?

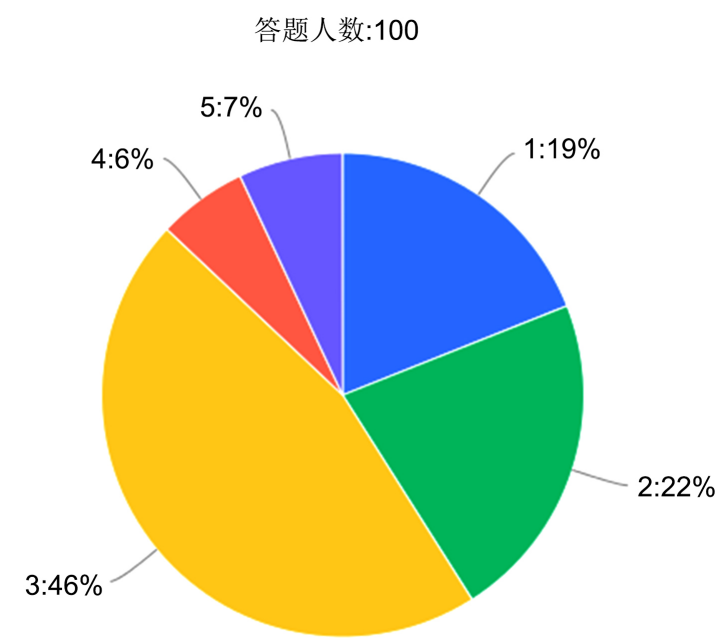

图 5. Q16 你对校园里庆祝圣诞节、情人节、感恩节等认可吗?

对本民族的传统和文化反认为是 “糟粕” 。Q25 “英语课上对西方文化的批 判多吗? ”中等以下选择否定答案的比例占 $53 \%$, 也就是说课堂上很少会批 判西方的文化。教师尚且如此, 学生又当如何呢? Q12 “英语教学、学习过 程中你接受过意识形态安全防范教育吗? ”选择平均以下否定回答的比例高 达 $74 \%$, 也就说学生在课堂上很少接触到意识形态安全防范教育。Q17 “你 能够用英语讲述中国故事吗? ” 选择较为肯定能够做到的人只有 $25 \%$, 而较 为肯定做不到的人占 $35 \%$, 反映出学生用英语讲述、传播中国故事的能力不 足, 有待提高。Q18 “和英语相比, 你在其它专业上花费的精力? ” 平均以 下否定回答的比例高达 $82 \%$, 说明被调查对象多数花在英语学习上的精力占 比很高, 一方面跟我国英语教育的大环境有关系, 另一方面也跟学生花费很 大精力备考英语等级考试有关, 对自己的专业反而忽视了。这样培养出来的 学生, 实则是在摧毁社会主义的核心价值观。这种现象与中央的教育工作会 
议精神背道而驰。

\section{4. 校园内外的社会大环境方面}

改革开放 40 年来, 外语教学改革成绩卓越的背后, 实为在该领域对我国 意识形态守候的缺失。现行大肆庆祝的 “洋节日”, 沾沾自喜的 “洋朋友”, 信手拈来英语词汇的口语化, 自幼儿园开始直到研究生阶段投入大量人力物 力精力孜孜以求的 “英语证书” ，由此可见一斑。一方面自然有 “英语” 自 身发展的历史原因形成了今天 “一语独大” 的世界地位, 也有我国的外语教 育政策使然, 但也的确反映出社会公众和大学生群体西方价值观的概念化和 民族信仰的遗失。Q19 “你有出国工作和生活的理想吗？”平均以上肯定回 答有出国工作和生活理想的人占比 39\%。而 Q20 “你对四个自信的认可度？” (图 6)有总共 $9 \%$ 的人选择较为否定的回答不太认可, 有 $28 \%$ 的人选择数字 3 一般认可, 选择最高级别数字 5 十分认可的人不足 $50 \%$ 。同样 Q21 “和西方 相比你对国内各方面的满意度” 选择平均以下否定回答不太满意的有 $34 \%$ 。 Q26 和英语国家相比对国产电影、书籍、商品的认可指数选择最高认可的只 有 $18 \%$ 。不得不说数据向我们传递了一种十分危险的信号。穆风良[7]的研究 还曾提及, 近代中国曾闯进来一位英国语言学家 Lugard, 为中国殖民化提出 了一项语言政策构想，最好让中国采用通用的外语作为统一的媒介，其结果 必然造成民族文化荡然无存。而反观我们长期以来盲目自信, 对此 “媒介” 带来的影响并没有多么重视。Q22 “如果有意识形态防范的讲座你会去听 吗?” 持明显否定态度不会去听的人占 $18 \%$, 选择数字 3一般的人占比 $43 \%$ 。 Q23 “你认为学习英语会受到西方意识形态的影响吗? ” 选择否定答案不太 会受影响的比例占 $82 \%$ 。Q28 “你对社会主义核心价值观的了解、认可程度” 选择最高级认可的仅有 $51 \%$ 。Q29 “你了解、学习马列、毛概等的认真和受 益指数” 持中等以下否定态度的占 $45 \%$ 。这更加证明当下的课程思政和民族 文化复兴指导思想的重要性, 值得我们好好参磨和实施。

答题人数: 100

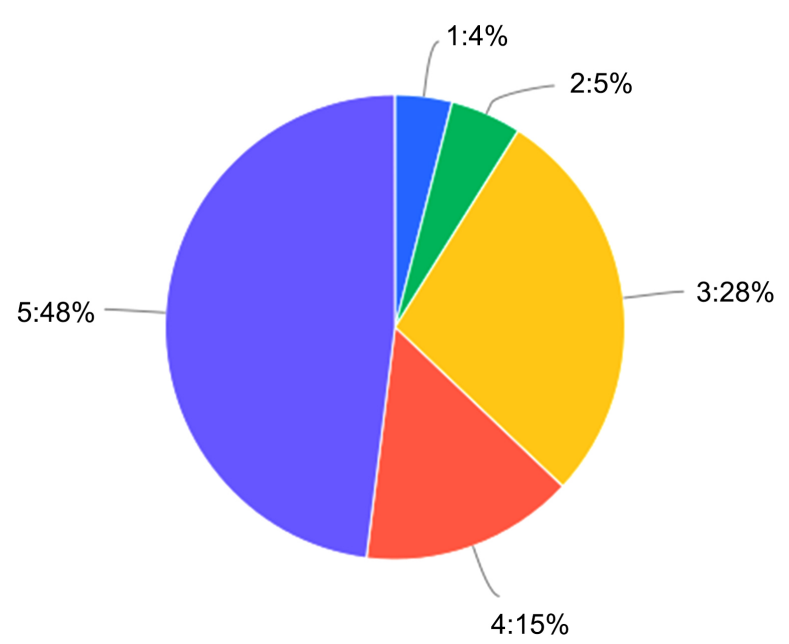

图 6. Q20 你对 “四个自信” 的认可程度? 


\section{5. 巩固高校英语教学意识形态安全的路径}

许多研究已经意识到了在高校外语教学领域维护我国意识形态安全的重 要性。但是要让高校英语教师真正普遍实施起来还是具有很大的难度, 毕竟 由于专业领域的限制和自身政治素养、政治敏感度的局限, 会有很多现实的 困难, 难有具体的抓手, 需要长期的思考和建设。本文尝试提出一些构思, 以供英语教育同行参考。

\section{1. 首先是思想认识方面}

Q30 多数被调查者提出首先和重点都是加强宣传, 提高认识。虽然说在 英语教学的各个环节都应该开展意识形态教育, 但是在高校群体中开展意识 形态教育是最合适的时机和最重要的阶段。大学生是社会知识、社会技能、 社会思潮的前沿群体, 是推动社会进步和发展的主力军。大学阶段正是其价 值观和人生观养成的重要时期, 并且对整个社会思潮具有引领作用。作为高 校英语教师, 必须首先完全接纳在英语教学中开展意识形态教育的必要性, 而不是选择性, 之后才能思考和执行具体的实施办法。

\section{2. 语言本体方面}

即使抛开政治层面的考量, 从专业角度也要关注语言本体层面的意识形 态问题，对英语的词汇、句式、时态、篇章等语言知识层面包含的衰贬意义、 群体喜好、隐喻概念要有深刻的认知和解读。比如说汉语中的裹义词翻译到 英语中很可能成了贬义词, 英语母语中把母亲(mother)作为开玩笑的对象是 十分平常并不是多么严重的问题, 汉语的谦虚表达在英语语境中并不能体现 出我们的高尚, 极其伤害我们民族自尊心的 “东亚病毒” 是英语造词的谬引 是可以沟通修正的, 将香港暴行分子描述为“protests”是明显带有双重标准的 扰乱行径。

\section{3. 教师政治修养方面}

教师原有的教育习惯和潜意识, 很大程度上影响着教育质量和人才培养 质量, 如果高校英语教师单纯从语言层面去搞语言教学和研究, 忽视文化传 播的影响, 潜意识里只会传播了西方的道德和价值观, 则不利于帮助学生形 成正确的道德理念和价值观。如何引导学生批判性解读学习材料内容, 才是 高校英语教学的重点, 换句话说, 主要是帮助学生批判性的解读语言学习的 素材, 正确评价其中暗含的东西方不同的社会规则和价值理念, 理解而不媚 外, 取其精华而去其糟粕, 强调 “四个自信”, 以弘扬中华传统优秀价值理 念为主要任务。因此教师自身政治修养和政治站位的提高十分关键, 自我教 育习惯和潜意识的升华十分重要。不能做一名两耳不闻窗外事, 一心只教圣 贤书的教书匠, 而要承担为国育才, 为党育人的新时代教育重担, 在教育教 学实践中, 平衡把握英语的工具和人文属性, 既要培养学生信息发掘和吸收 能力, 又要传播好中国声音, 讲好中国故事。在专业学习过程中, 多关注国 家大事, 将国家导向和声音搬进课堂就是很好的具体做法。 


\section{4. 互联网+创新方面}

在当代大众媒介环境下, 社会主义意识形态的传播不仅需要借助大众媒 介来进行, 同时也深受大众媒介的影响[11]。在互联网和大众媒介环境下, 教 育的 “课堂” 早已不是固定的教室。有一种声音说, 作为教师你从来都没玩 过王者荣耀, 没刷过抖音, 你如何了解你的学生? 暂且不对此声音本身作评 价, 互联网世界的推特、脸书、微博、抖音、游戏、网红、人肉、爬虫等等, 客观上确实存在大学生群体的娱乐至死对抗教师群体的一无所知! 在官方的 网络治理和主流媒体声音之后, 确实需要教育者更加熟悉当下大学生群体的 学习生活特征和价值取向, 以应对和创新教育教学中维护社会主义意识形态 安全的难题。

\section{5. 语言社会属性方面}

经济基础决定上层建筑, 随着中国经济社会的不断发展以及国际地位的 日益提高, “英语世界” 愿意附和、搭乘中国经济发展的便车, 愿意重新认 识和思考中国思维和中国智慧。许多的中式英语已广被接受, 中国方案正为 解决许多世界难题提供模板, 中国智慧正在日益受到更多关注。近日一位叫 马丁 - 雅克的英国教授在演讲中提到 “中国崛起不可怕, 可怕的是他们存在 5000 年还这么强” , 如今的世界正在步入一个 “中国化” 的时代。在我们维 系自己谦虚低调的文化传统之余, 国人更应该主动出击, 推动中国传统文化 词汇化、概念化进程, 提高自身思想国际化水平, 向世界自豪展现中华优秀 传统文化。教育的引导与肯定, 对青年群体的力量勃发至关重要。如年度文 化传播人物李子染坚持拍摄中华传统美食的短视频, 在国外收获了大量因此 爱上中国的粉丝, 虽然是个例, 却着实是青年一代优秀的榜样, 是课堂之上 应该肯定的正能量。

\section{6. 结论与展望}

综上所述, 意识形态本体研究受到普遍重视, 尤其是学科属性内的研究 较为深入, 而其它学科与意识形态相关性的研究较为薄弱。由于学科属性和 研究视角局限, 我国外语学科对意识形态问题的研究也较为浅显, 尤其是防 外意识不强, 甚至普遍麻㾇大意, 为我们的研究和教育敲响了警钟。要在思 想认识、语言本体、政治修养、互联网+创新、语言社会属性各个方面全面加 强意识形态教育和建设, 必须要树立正确的社会主义意识形态观。习近平新 时代中国特色社会主义意识形态是以人的全面发展为价值导向, 以社会主义 核心价值观为本质属性, 以 “四个自信” 为主要内容, 以 “两个巩固” 为根 本任务, 以 “不忘本来, 吸收外来、面向未来” 为建设原则, 以网络意识形 态建设为重点, 以中国叙述方式为基本特点, 以中华民族复兴为伟大使命, 以构建国际传播话语体系为新要求的理论体系[12]。在前期调研中我们悲观的 发现, 多数高校英语教师对代表国家主流意识形态的 “语言文本” 从未主动 解读或深刻思考, 甚至知之甚少, 又怎能在教育教学过程中正确引导和培养 学生呢? 虽然不是要求英语教师都去学政治学, 但是自觉关注国家大政方针 
与政策导向, 研读理解国家的 “语言文本” , 培养学生的跨学科视野, 关注 专业教学的意识形态安全, 是课程思政背景下高校英语教学必须加入的重要 内容和具体抓手。

\section{Conflicts of Interest}

The authors declare no conflicts of interest regarding the publication of this paper.

\section{References}

[1] 司显柱. 试论我国高校英语教学中的意识形态[J]. 语言教育, 2018(2): 2-4.

[2] 俞吾金. 意识形态: 哲学之谜的解答[J]. 求是学刊, 1993(1): 3-7.

[3] 宋广强, 章风红. 当代中国意识形态安全面临的挑战与对策 [J]. 思想理论教育导 刊, 2015(5): 103-106.

[4] 王永贵, 路媛. 网络空间主流意识形态认同困境及其路径创新 [J]. 理论探索, 2019(3): 49-54.

[5] 李春阳. 美国几个主要意识形态输出机构状况 [J]. 国际研究参考, 1991(8): 26-29.

[6] 韩健鹏. 当代西方意识形态新变化对中国意识形态安全的影响与对策[D]: [博士 学位论文]. 吉林: 吉林大学行政学院, 2012.

[7] 穆风良. 外语教学中的意识形态思考[J]. 清华大学教育研究, 2003(S1): 53-57.

[8] 王景洁. 大学英语教学中的社会主义意识形态的培养 [J]. 课程教育研究, 2019(18): 119.

[9] 夏远超. 对西方“英语帝国主义”影响下中国高校英语教学的思考[J]. 教育园地, 2009(2): 213-214.

[10] 王祥兵. 论《时代》周刊中国报道文章对汉语文化词语的翻译[J]. 上海科技翻译, 2002(2): 19-22.

[11] 何红连. 大众媒介环境下社会主义意识形态传播问题研究 [D]: [博士学位论文]. 上海: 华东师范大学人文社会科学学院社会科学部, 2014.

[12] 武振华. 论习近平对中国特色社会主义意识形态理论的贡献[J]. 吉林师范大学学 报(人文社会科学版), 2019(3): 79-87.

\section{Appendix (Abstract and Keywords in Chinese) 课程思政背景下再论高校英语教学中的意识形态问题}

摘要: 意识形态问题研究由来已久, 却鲜有触及高校教学领域。而高校 大众对意识形态问题的麻木甚至不以为然恰恰是当下应对意识形态问题最大 的危机。本文调查、分析了当下课程思政背景下, 高校英语教学中意识形态 问题在认知、环境、特征、举措方面的数据, 并从思想认识、语言本体、政 治修养、互联网+创新、语言社会属性五个方面提出了巩固意识形态安全的路 径, 符合当下课程思政建设的教育教学要求和国家发展需要。

关键词: 意识形态, 英语教学, 课程思政 